\title{
Imigração de nordestinos para Roraima
}

\author{
ANA LIA FARIAS VALE
}

$\mathrm{N}$ O PROCESSO do conhecimento científico, a teorização e a investigação acham-se indissoluvelmente ligadas; a relação entre ambas constitui o motor de partida fundamental do conhecimento. A migração interna, nas duas últimas décadas, vem desenvolvendo esforços de investigação relacionados com diferentes aspectos do fenômeno. Até certo ponto, é possível dizer que, na maioria dos casos, as investigações vêm ocorrendo sem se recorrer às teorias ou aos marcos. Muitas dessas investigações se mostram permeáveis à influência exercida pelos marcos teóricos que, paralelamente, se vão desenvolvendo na época de sua realização.

Para enquadrar a maior parte da produção teórica sobre migrações, as escolas, correntes teóricas e variantes de comum substrato num mesmo tronco, Salim (1992, p.121) e Póvoa-Neto (1997, p.12) usam a expressão "tronco teórico", propondo criar uma classificação em três troncos principais.

O primeiro, um conjunto de autores que faz uso de uma concepção neoclássica do espaço e das migrações, que se preocupa com a economia do espaço e a gestão capitalista da mão-de-obra - nesse caso, as migrações não têm apenas concepção demográfica, mas principalmente econômica de inspiração walrasiana de valor utilidade e a sua interdependência dos fenômenos de mercado -; o segundo, chamado de perspectiva histórico-estrutural, vinculada à tradição dialética do marxismo e responsável por vasta produção crítica sobre a migração, analisa grupos e classes sociais a sofrer as forças das estruturas sociais que explicam a maior ou menor propensão a migrar; o terceiro, a mobilidade da força de trabalho, na qual os economistas clássicos procuram fazer uma nova análise da migração no processo de acumulação capitalista, em que a migração, afirmam, não pode ser encarada fora da realidade do trabalho social, e sim como pressupostos econômicos desse.

Os três troncos teóricos colocam cada trabalho no centro de sua análise. $\mathrm{Na}$ qualidade de fator produtivo, a mobilidade populacional é tema que interessa diretamente ao estudo dos assuntos pertinentes ao homem, pelos efeitos que exerce sobre a distribuição da população e por sua interação com outras forças demográficas, bem como com outros aspectos das mudanças e das diferenciações sociais e econômicas.

A migração, segundo Salim (1992, p.122), é um fenômeno complexo, essencialmente social, com determinações diversas; apresenta interações particulares com as heterogeneidades de uma formação histórico-social concreta que 
tende a assumir feições próprias, diferenciadas e com implicações distintas, para os indivíduos ou grupos sociais que a compõem e a caracterizam.

$\mathrm{O}$ fenômeno da migração relacionada às condições históricas das mudanças (social, econômica, estrutural etc.), afirma Salim (1992), constitui importante mecanismo de reprodução ou alteração numérica da sociedade. Podem-se medir ou refletir processos que se refletem indiretamente sobre outros processos demográficos ou, diretamente, sobre as relações de classes que determinam a formação e a composição do mercado de trabalho de um território.

No Brasil, o deslocamento de populações de áreas da Região Nordeste para as áreas da Amazônia tem sido bem documentado e desempenha papel proeminente em muitas estratégias de desenvolvimento econômico do governo federal. No entanto, o rápido e desorientado crescimento que se vem observando na Amazônia, principalmente a partir da década de 1980, gera dúvidas sobre os benefícios desses deslocamentos maciços de população, dúvidas essas que dizem respeito tanto aos próprios migrantes como aos que se dedicam ao estudo do desenvolvimento do país.

Uma das evidências dos resultados negativos da transferência de populações refere-se ao elevado ritmo do aumento demográfico, desproporcional ao que os governos implantam em infra-estrutura, acarretando problemas já conhecidos pelas comunidades dos grandes centros urbanos.

Em Roraima, extremo norte da Amazônia, a migração traz à tona o problema das territorialidades, ${ }^{1}$ que, segundo Barros (1998, p.127), se apresenta na área como muito complexo. Havia um equilíbrio tribal territorial na base da força de grupos indígenas e de suas preferências de sítios e difusões pré-colombianas, como makuxis, yanomamis, taurepangs, wai-wais etc. Sem que essas territorialidades fossem apagadas totalmente, difundiram-se as territorialidades lusa, hispânica e holandesa/britânica, configurando novos recortes de domínio territorial e demográfico-étnico que acabaram por criar as fronteiras dos estados, nações emergentes da descolonização.

As territorialidades foram se superpondo - grupos indígenas/aldeias e estado/criadores e fazendas -, fundindo-se à sociedade expansiva (provocando muitas tensões sócio-culturais-espaciais), além da intervenção federal sobre a área que pertencia ao Amazonas, com a criação do território federal em 1943, e a partir de 1988 a transformação em Estado, criando a partir de então base administrativa, mas cuja dependência financeira, política e cultural quase total a esse poder federal prolonga-se até os dias atuais (Barros, 1998).

Há domínio de subterritórios em Roraima: instituições federais como Ibama, com reservas ecológicas; Funai, com áreas indígenas com domínio territorial representando quase metade da superfície do Estado; Incra, com projetos de assentamento familiar onde o domínio territorial chega a três quartos da superfície estadual; além de igrejas que fomentam a consolidação de áreas indígenas; ecologistas com áreas de preservação ambiental criadas pelo governo federal, garimpeiros sobrepõem-se ao território indígena e à criação de novos 


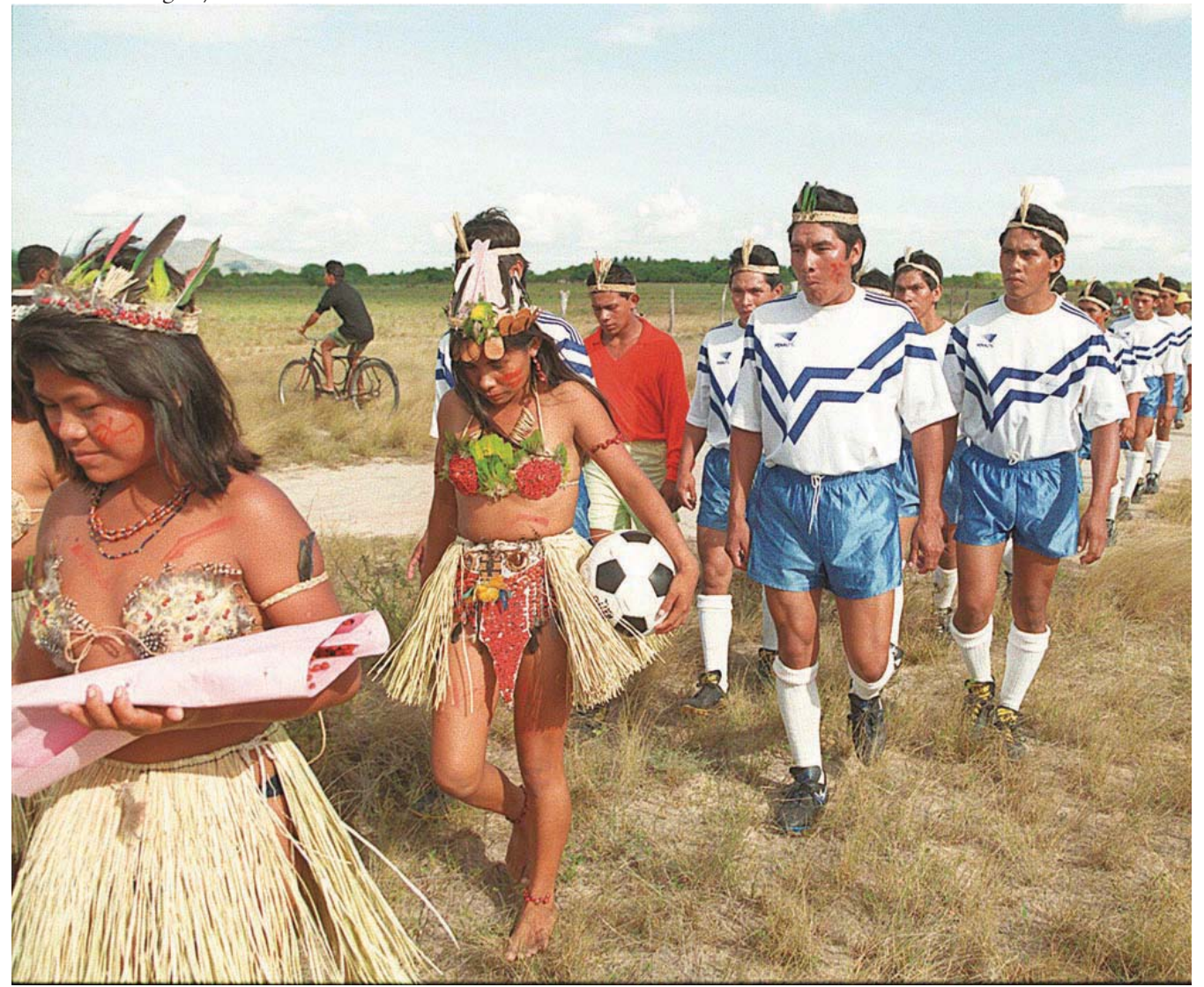

Equipe da tribo macuxi entra em campo seguindo as indias "mascotes", em Normandia (RR). municípios (em 1996 foram criados sete municípios), endentando-se com reservas ambientais e áreas indígenas.

O nordestino é responsável pela mais recente territorialidade, ocorrida em Roraima; em particular o maranhense, que vem produzindo novas territorialidades e novas formas de concepção do uso e do processo de domínio do território de caráter econômico e social, com uma carga de influência absorvida pela população nativa expressa em nome de estabelecimentos comerciais, nome de bairros, grupos folclóricos, nomes de pessoas etc., havendo, dessa forma, uma nova territorialização do espaço roraimense, que se modifica por meio da influência de um povo simples, que mantém valores tradicionais do lugar de origem.

\section{Reprodução do espaço de Boa Vista - território nordestino}

A produção de um determinado espaço é resultado do nível de integração entre os diferentes elementos da paisagem natural (clima, hidrologia, vegetação) e paisagem cultural (expressão máxima da área orgânica), relacionados diretamente a diferentes usos do tempo (simultâneos e sucessivos). A posição do homem e suas relações constituem o mais importante fator de influência na gênese das formas da paisagem, sujeitas a mudanças pelo desenvolvimento de técnicas ou sobreposição de culturas, em que o homem expressa o seu lugar na natureza como um agente modificador das condições naturais originais. 


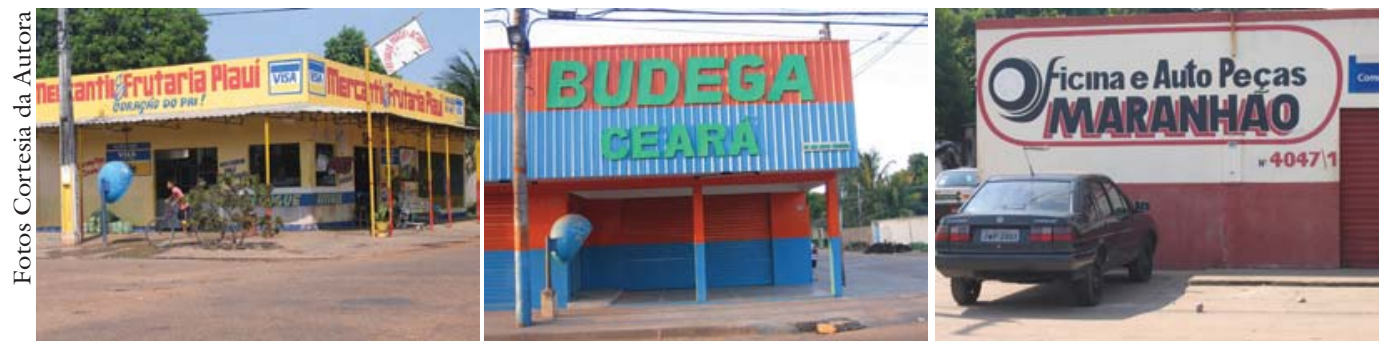

Figura 1 - Territorialidade nordestina em Boa Vista/RR. ${ }^{2}$

Deve-se analisar a produção do espaço levando em consideração as diferentes apropriações do solo que são justapostas entre si. Essa complexidade territorial é simultaneamente fragmentada e articulada, o que denota que esse espaço urbano é um reflexo de sua sociedade. São os agentes sociais que fazem e refazem a cidade. Esses agentes podem ser os proprietários dos meios de produção, os proprietários fundiários, os promotores imobiliários, o Estado e os grupos sociais excluídos.

As diferentes territorialidades adquiridas pelos migrantes na diversidade dos espaços, por ele anteriormente territorializados, são culturas que se justapõem, resultando numa reterritorialidade própria ainda trabalhada, não definida, vendo que esse processo ainda está por acabar, pois a dinamicidade do cotidiano é vital, no qual as territorialidades se nutrem de uma especialidade/temporalidade. Novas e velhas territorialidades se agregam, reproduzindo o espaço; assim, transformam o migrante num ator na reprodução e, por sua vez, a migração passa a ter um papel de agente.

A população de Roraima, com base no Censo de 1991, era de 217.583 habitantes; desses, 146.769 na zona urbana e 70.814 na zona rural. No Censo de 2000, o total é de 324.397 habitantes, dos quais, 247.016 estão na zona urbana e 77.381, na zona rural. Com as estimativas que o IBGE/RR trabalha para 2005, percebe-se a intensa mobilidade, que atingiu uma população de 391.317 habitantes, com uma densidade demográfica relativamente baixa de $1,73 \mathrm{hab} / \mathrm{km}^{2}$; contudo concentrada na cidade de Boa Vista, com uma população em torno de 242 mil habitantes. $^{3}$

Foi levantado um diagnóstico socioeconômico dos moradores da cidade de Boa Vista pela prefeitura municipal em 2001 (atualizado em 2003), em 42 bairros (dos cinqüenta que a cidade possui), no qual se avaliou quantitativa e qualitativamente uma população de 188.131 pessoas ( 50.156 famílias em 47.908 domicílios) (Tabela 1).

Um dos pontos levantados diz respeito à origem do chefe de família economicamente ativo, vindo a confirmar o que já é percebido na cidade: o domínio de um território culturalmente nordestino, predominando chefes de família nascidos no Maranhão (12.458). Contudo, a instabilidade econômica (maior número, não somente de maranhenses, mas dos demais migrantes analisados, como autônomo sem registro, empregado sem registro, bico e desempregado) é um 
problema que segue junto ao ato de migrar, mesmo se a migração for resultante da mobilidade da força de trabalho, pois a seletividade é um dos componentes das trajetórias migratórias que refletem os inúmeros obstáculos impostos à mobilidade social ascendente pela dinâmica econômica e social no Brasil. As trajetórias e a sua seletividade só podem ser compreendidas se esse for considerado um país que cultua a migração, com trajetórias estruturadas e que assumem importância dentro da dinâmica econômica e social, porque existe uma forte cultura ou "tradição migratória".

Tabela 1 - Situação ocupacional dos chefes de família economicamente ativos em 2003, segundo a naturalidade

\begin{tabular}{|c|c|c|c|c|c|c|c|c|c|c|}
\hline ESTADOS & $\begin{array}{l}\text { Empre- } \\
\text { gado } \\
\text { com } \\
\text { registro }\end{array}$ & $\begin{array}{l}\text { Empre- } \\
\text { gado } \\
\text { sem } \\
\text { registro }\end{array}$ & $\begin{array}{c}\text { Fun- } \\
\text { cionário } \\
\text { público }\end{array}$ & $\begin{array}{c}\text { Au- } \\
\text { tônomo } \\
\text { com } \\
\text { registro }\end{array}$ & $\begin{array}{c}\text { Au- } \\
\text { tônomo } \\
\text { sem } \\
\text { registro }\end{array}$ & $\begin{array}{l}\text { Ambu- } \\
\text { lante/ } \\
\text { camelô }\end{array}$ & Bico & $\begin{array}{l}\text { Empre- } \\
\text { gador }\end{array}$ & $\begin{array}{l}\text { Desem- } \\
\text { pregado }\end{array}$ & Total \\
\hline Maranhão & 1.849 & 2.043 & 1.608 & 291 & 3.271 & 72 & 1.654 & 28 & 1.642 & 12.458 \\
\hline Roraima & 1.392 & 1.901 & 2.662 & 193 & 1.968 & 21 & 1.232 & 12 & 1.597 & 10.978 \\
\hline Pará & 569 & 685 & 527 & 76 & 787 & 18 & 449 & 11 & 548 & 3.670 \\
\hline Amazonas & 502 & 588 & 819 & 82 & 748 & 16 & 369 & 12 & 496 & 3.632 \\
\hline Ceará & 345 & 393 & 507 & 125 & 783 & 25 & 283 & 17 & 328 & 2.806 \\
\hline Piauí & 195 & 222 & 221 & 50 & 404 & 15 & 170 & 4 & 182 & 1.463 \\
\hline Paraná & 71 & 86 & 106 & 28 & 182 & 1 & 35 & 4 & 61 & 574 \\
\hline R. G. Norte & 81 & 67 & 99 & 25 & 127 & 3 & 40 & 3 & 45 & 490 \\
\hline Paraíba & 63 & 62 & 127 & 18 & 112 & 1 & 33 & 6 & 57 & 479 \\
\hline $\begin{array}{l}\text { Pernam- } \\
\text { buco }\end{array}$ & 64 & 69 & 119 & 18 & 97 & 1 & 31 & 0 & 50 & 449 \\
\hline Tocantins & 53 & 79 & 53 & 14 & 127 & 0 & 50 & 3 & 48 & 427 \\
\hline $\begin{array}{l}\text { Minas } \\
\text { Gerais }\end{array}$ & 58 & 58 & 83 & 21 & 104 & 3 & 37 & 10 & 39 & 413 \\
\hline São Paulo & 61 & 57 & 83 & 17 & 123 & 1 & 15 & 6 & 40 & 403 \\
\hline R. G. Sul & 53 & 43 & 101 & 28 & 106 & 0 & 22 & 6 & 25 & 384 \\
\hline Goiás & 29 & 45 & 52 & 23 & 123 & 1 & 30 & 3 & 46 & 352 \\
\hline Bahia & 43 & 55 & 52 & 7 & 108 & 3 & 24 & 2 & 50 & 344 \\
\hline Rondônia & 49 & 58 & 50 & 7 & 83 & 3 & 25 & 0 & 55 & 330 \\
\hline R. Janeiro & 58 & 33 & 133 & 11 & 34 & 1 & 4 & 0 & 22 & 296 \\
\hline Acre & 41 & 36 & 51 & 2 & 60 & 1 & 20 & 1 & 25 & 237 \\
\hline $\begin{array}{l}\text { Mato Gros- } \\
\text { so do Sul }\end{array}$ & 23 & 34 & 32 & 4 & 51 & 1 & 19 & 1 & 22 & 187 \\
\hline $\begin{array}{l}\text { Mato } \\
\text { Grosso }\end{array}$ & 25 & 35 & 31 & 5 & 46 & 0 & 12 & 0 & 22 & 176 \\
\hline $\begin{array}{l}\text { Espírito } \\
\text { Santo }\end{array}$ & 17 & 16 & 23 & 4 & 40 & 4 & 13 & 0 & 14 & 131 \\
\hline $\begin{array}{l}\text { Santa } \\
\text { Catarina }\end{array}$ & 8 & 12 & 19 & 10 & 32 & 0 & 8 & 2 & 8 & 99 \\
\hline Alagoas & 17 & 7 & 17 & 3 & 23 & 0 & 10 & 0 & 10 & 87 \\
\hline $\begin{array}{l}\text { Distrito } \\
\text { Federal }\end{array}$ & 10 & 12 & 20 & 4 & 12 & 0 & 1 & 1 & 12 & 72 \\
\hline Sergipe & 10 & 6 & 6 & 1 & 11 & 0 & 2 & 1 & 4 & 41 \\
\hline Amapá & 6 & 4 & 7 & 0 & 8 & 1 & 2 & 0 & 6 & 34 \\
\hline Total & 5.692 & 6.706 & 7.608 & 1.067 & 9.570 & 192 & 4.590 & 133 & 5.454 & 41.012 \\
\hline
\end{tabular}

Obs.: 2.325 chefes de família não informaram a naturalidade.

Fonte: Programa Braços Abertos da Prefeitura Municipal de Boa Vista -

Secretaria Municipal de Gestão Participativa e Cidadania, dados coletados em 2003. 
Estão incluídos nos funcionários públicos antigos funcionários da União ${ }^{4}$ justificando o porquê de a maioria dos chefes de família ser de origem roraimense (2.662 dos 7.608 chefes de família entrevistados). Os funcionários que pertencem ao atual quadro funcional do Estado são migrantes que adentraram a partir dos anos 1990, predominando os nascidos no Maranhão, no Amazonas e no Pará.

Nas entrevistas, ficou evidente que os migrantes estão contribuindo de alguma forma para a revitalização da economia local, ao mesmo tempo que houve alteração dos níveis de renda, assim como aumento nos rendimentos da população migrante, significando que a articulação dada pelos fluxos populacionais melhora o posicionamento na pirâmide social e dinamiza economicamente espaços. Não obstante o fato de ocorrer um aumento dos migrantes ocupados e com melhores rendimentos, pois, como demonstra a Tabela 1, os desempregados são aproximadamente $13,2 \%$ dos entrevistados.

Há evidências de que Roraima desenvolve relações intensas com o restante do país, mesmo que esteja fora dos tradicionais "campos aglomerativos" e "polígonos de desenvolvimento". É perceptível a ampliação dos canais de transmissão de fluxos de outras regiões, mais vinculadas a processos de desenvolvimento tecnológico avançado.

Boa Vista cresce, demograficamente, pelo setor terciário, e esse incremento populacional, e conseqüentemente a reprodução do espaço urbano de Boa Vista, pode ser avaliado por fases que são nitidamente diferenciadas; contudo, todas com o mesmo intuito da superação da crise econômica que o país vem atravessando há décadas, resultando num constante fluxo interno de famílias. Assim, a migração se utiliza do momento em que existem projetos sociais, incentivada pela doação de terras, casas, emprego; enfim, programas sociais (principalmente em período que antecede campanhas políticas eleitorais).

Roraima, com o passar dos anos, terá uma das populações mais mescladas do Brasil. Índios de várias tribos, garimpeiros de todas as regiões, militares, colonos migrantes, transformando o território, com características assimiladas de todos, com formação de novas territorialidades e novas formas de concepção do uso e do processo de domínio do território de caráter econômico e cultural.

\section{Notas}

1 A expressão territorialidade pode ser encarada tanto como o que se encontra no território e está sujeita à gestão do mesmo quanto, ao mesmo tempo, o processo subjetivo de conscientização da população de fazer parte de um território, de integrar-se a ele.

2 Mercantil e Frutaria Piauí, Av. Felipe Xaude com Horácio Magalhães, 2476, Bairro Asa Branca; Oficina e Autopeças Maranhão, Av. Mario Homem de Melo, 4047, Bairro Buritis; Budega Ceará, Rua Sólon Rodrigues Pessoa, 884, Bairro Pintolândia. 
3 Dados coletados no IBGE/RR por intermédio do diretor regional Sr. Joaquim Vicente de Paula, em novembro de 2005.

4 Roraima, até 1988, era território federal e todos os funcionários públicos pertenciam ao quadro da União; eram, portanto, funcionários públicos federais.

\section{Referências bibliográficas}

BARROS, N. C. de C. A reconversão do "Eldorado" pela expansão dos serviços das frentes agrominerais às frentes ecoturísticas na bacia do rio Branco, Roraima, Brasil. Boa Vista. In: VASCONCELOS, F. P. (Org.) Turismo e meio ambiente. Fortaleza: UECE, 1998. p.109-37.

IBGE. Censo 2000. Preliminares. Disponível em: <http://www.ibge.com.br>. Rio de Janeiro: nov. 2000. Acessado em: 30.5.2005.

PÓVOA-NETO, H. Migrações internas e mobilidade do trabalho no Brasil atual: novos desafios para a análise. Revista e Experimental, São Paulo, n.2, p.11-24, março 1997.

SALIM, C. A. Migração: o fato e a controvérsia teórica. In: VIII ENCONTRO NACIONAL DE ESTUDOS POPULACIONAIS. Anais... Campinas: Abep. 3, p.119144, 1992.

RESUMO - ESTE ARTIGO apresenta sucintamente os limites das teorias sobre as migrações internas dando especial destaque o fluxo ocorrido entre o Nordeste e a Amazônia brasileira, numa tentativa de esboçar algumas reflexões sobre migração como agente na (re) produção do espaço, com identidades culturais espelhadas na paisagem urbana, com territorialidades objetivas e subjetivas, adquiridas pelos espaços (lugares) anteriormente percorridos na longa trajetória dos atores (migrantes), esboçando permanentemente identidades que compõem um território com amplitudes culturais novas e diversas.

PALAVRAS-CHAVE: Migração, Territorialidade, (Re)produção do espaço.

ABSTRACT - THIS ARTICLE presents a brief theory about the internal migrations giving a special emphasis on the flux that occur between Northeast and the Brazilian Amazon with an attempt to design reflections about migration as a (re) production of space (places) agent, with cultural identities and reflections of urban scene, with objective and subjective territorialities, acquired during the long course of the actors (migrants), creating permanently, identities that formed a territory with new and diverse cultures.

KEYWORDS: Migration, Territoriality, (Re)production of space.

Ana Lia Farias Vale é professora da Universidade Federal de Roraima, doutoranda em Geografia na Universidade Estadual Paulista (Presidente Prudente) (FCT/ Unesp), bolsista da Capes/PICDT. @ - lialuz@netsite.com.br

Recebido em 3.6.2006 e aceito em 6.6.2006. 